chapter, providing a deft portrait of Barrow and a concise history of the North Slope and the Inupiat. The result is an excellent book about a remarkable woman. Blackman's own text is informative without being obtrusive. It includes comments about Sadie made by colleagues and friends, and fills out our view of Sadie without overshadowing Sadie's words. Sadie's stories give insight into Native life in Barrow, the struggles of modemization, and the transformations which she has helped her home town to undergo while retaining the vitality of its Inupiaq culture. (Henry P. Huntington, Scott Polar Research Institute, University of Cambridge, Lensfield Road, Cambridge CB2 1ER UK.)

\section{THE ORIGINS OF MAN}

CHILDREN OF THE ICE: CLIMATE AND HUMAN ORIGINS. Gribbin, J. and M. 1990. Oxford, Basil Blackwell. $199 \mathrm{p}$, hard cover. ISBN 0-631-16817-6. $£ 15.95$.

A work of popular science, and a miracle of condensation in view of its awe-inspiring time-scale, this book attempts a layman's exposition of the origins and evolution of mankind set in the context of changing world climates. It is a synthesis of other books by the same authors in these and related fields and derives from a BBC Radio Four series of the same title. The question that the Gribbins set out to answer is 'Why are we here?'. How is it that humans are among the most successful forms of life on Earth today? The story begins about 370 million years ago with the emergence on land of our ancestors the amphibians. The consequent evolutionary processes and their speculative causes are discussed with frequent side-tracking into such disciplines as geology, palaeontology and cosmology.

The chief mechanism for effecting climatic change is seen by the authors as continental drift. Thus a fragmenting of Gondwanaland some 65 million years ago brought about the catastrophic global cooling which in turn led gradually to the extinction of the once all-dominant dinosaurs, allowing the mammals to achieve prominence. During the Quaternary continental drifting brought about the spread of ice in high latitudes, the first in a series of ice ages, broken by short interglacial periods, which gave rise to the evolutionary events which forced some tree-dwelling apes out of the African forest to evolve into Homo erectus. To respond to climatic challenges this creature increased the size of its brain pan to become Homo sapiens about 100,000 years ago. Thus, the authors claim, we can today truly call ourselves 'children of the ice'.

The rest of the book lies mosuly in the realm of history. During the ice ages Homo sapiens completed the peopling of the world. In a few brief pages we see how climate affected the great migrations, the rise and fall of empires, the Viking colonies in Greenland and their failure due to a 16th-century cooling. More recently frost fairs on the Thames, Dickensian Christmases and the Irish potato famine are among the numerous examples of climatic determinism. Finally a glimpse into the future warns predictably of the consequences of our profligate use of fossil fuel and the consequences of global warming due to man himself, ultimately leading to a return to the 'dinosaur days'. In conclusion the authors furnish us with an appendix giving an explanation of the cause of ice age cycles in the light of recent research. This is a stimulating and controversial book. An evolutionary time-scale is the sole visual aid though - more would have been helpful. (H. G.R. King, Scott Polar Research Institute, University of Cambridge, Lensfield Road, Cambridge CB2 1ER UK.)

\section{DEVELOPMENT OF A CULTURE}

THE INUPIAT AND ARCTIC ALASKA: AN ETHNOGRAPHY OF DEVELOPMENT. Chance, N. A. 1990. Fort Worth, Holt, Reinhart and Winston. (Case studies in cultural development). $242 \mathrm{p}$, illustrated, soft cover. ISBN 0-03-032419-X.

This volume is a welcome addition to a series of case studies in cultural anthropology, aimed at undergraduates in the social sciences. As such, it also supplements the author's previous book for the same series The Eskimo of North Alaska (1966). That work was based on fieldwork carried out on the North Slope in the late 1950s and early 1960s. Taking a community-focused approach, the study examined economics, kinship, the socialization of children and local politics. While describing traditional Inupiat lifeways, Chance discussed recent social change and demonstrated the positive nature of cultural integration. Like many anthropologists at the time, he was guided by a 'functionalist' perspective (with its emphasis on social harmony) and theories of 'westernization'. This latest work aims to correct Chance's earlicr theoretical influences, by considering the effects of colonialism and its accompanying social and economic exploitation.

After setting the scene with a history of the first migrants into Alaska, right up to encounters with Russian and American colonialists, Chance draws on his earlier fieldwork in giving us a picture of Inupiat social life. While details of traditional culture are outlined, the effects of Euro-American influence are examined. Throughout, the emphasis is on the Inupiat response to colonialism and development; the introduction of new technology into the subsistence economy, improved health care, education, Christianity and the erosion of shamanism, epidemics because of western diseases, and the emergence of a wage economy.

Based on more recent research, the author devoles the final part of the book to threats to Inupiat culture, land, and Native rights owing to the development of oil and gas exploitation. This section comes across as a clear and penetrating analysis of the responses to economic development in Arctic Alaska. Following the discovery of oil at Prudhoe Bay, the Inupiat have had to deal with pressing contemporary change that has seriously harmed and eroded their cultural life. Chance discusses this, together with land claims settlements, the establishment of corporations, the defence of subsistence rights and cultural identity. The latter is of deep concem for the future. Inupiat economic and social life has been transformed by 
a long historical process of contact, one that intensified with the exploitation of oil. Despite social stratification, the importance of a wage economy, threats to kin-based ties, and the decline of the Inupiat language, there is a growing emphasis on Inupiat cultural distinctiveness. This finds an expression through whaling and sharing. It has the effect of acting as a symbolic boundary between the Inupiat and the outside world, signalling cultural identity at a time when such identity needs to be strong enough to counter internal tensions. The author considers cultural identity and the persistence of kin-based networks as necessary for articulating the relationship between Inupiat and their ancestral lands. This has a particularly strong significance in the light of recent environmental disasters, such as Exxon Valdez, and atmospheric pollution.

Chance succeeds in his aim of demonstrating the need to re-evaluate where human societies stand in relation to their utilization of nature. By so doing he gives his book a wider application beyond Alaska and the Arctic. Wecan understand development and culture change in relation to historical connections only in a wider world system. The Inupiat, while unique in their own right, share compelling similarities and problems with other aboriginal peoples. Development means social and psychological dislocation in many parts of the world. This book should be read as an example of what one group of people have undergone, where they now stand, and the prospects they face for the future. (Mark Nuttall, Scott Polar Research Institute, University of Cambridge, Lensfield Road, Cambridge CB2 1ER UK.)

\section{HOT CONFLICTS, COLD REALITIES}

THE AGE OF THE ARCTIC. Osherenko, G. and Young, O. R. 1989. Cambridge, Cambridge University Press (Studies in Polar Research). 316 p, illustrated, hard cover. ISBN 0-52136451-5. £37.50, US\$59.50.

Scientists who expect from this title a geological or palaco-glaciological treatise will be disappointed, for this is a book on Arctic politics. No-one else need be disappointed, for it is a good book, and anyone who works in or thinks about the Arctic would benefit from reading it. The subject matter, more accurately expressed in the subtitle 'Hot conflicts and cold realities', concerns scientists as much as anyone else. The book is about conflict in the Arctic - conflict of all kinds from parish-pump to regional, from national to international - which in one way or another characterizes Arctic affairs. Military and civil powers, scientists, politicians, doctors, lawyers, and certainly Indian chiefs: all are involved as protagonists. The authors, a political scientist and a lawyer, write of conflicts between states over national security, conflicts in Arctic economics and industrial developments, conflicts involving native interests, and conflicts over ecological matters, all issues on which ding-dongs of varying intensity are currently raging.

Accounts of these problems occupy the first half of the book: the second half, under the section title 'Handling Arctic conflicts' applies conflict theory to the issues and deals where possible with remedies and solutions. The writers draw heavily on North American examples and data, but are sufficiently pan-Arctic to make the book of universal interest. This is a solid, well-considered work, one to be recommended strongly to anyone concerned with courses in polar studies, and to postgraduate students in any field of Arctic enquiry. The writing is sometimes heavy-going, with an old-fashioned textbook gravitas, but thorough and worth the effort of reading. (Bernard Stonehouse, Scott Polar Research Institute, University of Cambridge, Lensfield Road, Cambridge CB2 1ER.)

\section{SOUTH PACIFIC SECTOR}

ANTARCTIC SECTOR OF THE PACIFIC. Glasby, G. P. (editor). 1990. Amsterdam,Elsevier. (Elsevier Oceanography Series 51). 396 p, illustrated, hard cover. ISBN 0-444-88510-2. US\$97.50, Df1 190.00.

The Southern Ocean is usually treated oceanographically as a circumpolar entity. This book reminds us that it can instead be regarded as a series of adjoining sectors, and sets out to summarize what is known of the sector immediately south of the Pacific Ocean. Containing some of the world's roughest seas, and bounded in the south by some of the most ice-bound stretches of Antarctic coasts, much of this sector has understandably been neglected. The exception is the Ross Sea region, immediately south of New Zealand, which in contrast is among the most hospitable of all polar oceanic regions in summer, usually allowing safe access by ship to $78^{\circ} \mathrm{S}$.

This book covers the region from New Zealand east to South America and Antarctic Peninsula, to an indefinite northern boundary in about $45^{\circ} \mathrm{S}$. It comprises 11 papers, mainly by New Zealand and US authors. An historical overview by the editor is followed by papers on Meteorology (Mullan and Hickman), Physical oceanography (Patterson and Whitworth), Ice (Keys), Structure and tectonics (Davey), Hydrocarbon exploration and potential (Cook and Davey), Sediments (Anderson), Plankton (El-Sayed), Marine mammals (Baker), Seabirds (Harper, Spurr and Taylor), and Environmental and pollution aspects (Gregory).

This is not an original formula for an Antarctic book, and there is an air of inevitability over a few of the chapter titles and names - haven't we seen just such a paper by that author before? However, everyone manages some degree of originality, and the overall impression is refreshing: these workers find interest and uniqueness in their sector and are generally up-to-date in telling us about it. The final chapter on pollution is a welcome innovation: I should have welcomed also a chapter on fish, including industrial fishing, which may be becoming more prominent in the area, and is clearly responsible for a deal of harmful debris in the ocean. Editing is to a high standard, all references are together in a single listing at the end, and there is an adequate index.

Should this book pay its way, I wonder if the publishers would consider similar regional accounts of the Atlantic and Indian Ocean sectors? Antarctic sector of the Pacific is available in Europe from Box 211, $1000 \mathrm{AE}$ 